\title{
On Probability Distribution of Chloride Diffusion Coefficient for Recycled Aggregate Concrete
}

\author{
Jingwei Ying ${ }^{1,2)}$, Jianzhuang $\mathrm{Xiao}^{2), *}$, and Qiujiang Meng ${ }^{1)}$ \\ (Received August 12, 2015, Accepted December 20, 2015, Published online January 22, 2016)
}

\begin{abstract}
In predicating the probability distribution of chloride diffusion coefficient of recycled aggregate concrete $\left(D_{\mathrm{RAC}}\right)$, the morphological characteristics of three phases, i.e., the old attached mortar, the natural aggregate and the new mortar, should all be taken into account. The present paper attempts to develop a probability density evolution method (PDEM) to achieve this. After verifying the derived PDEM results with experimental results, the effects of old attached mortar to the $D_{\text {RAC }}$ are examined in a quantitative manner. It is found that (1) the variation of the attached mortar content is much sensitive to $D_{\text {RAC }}$; (2) given the probability distribution of the content and chloride diffusion coefficient of old mortar, the probability distribution of $D_{\mathrm{RAC}}$ can be analysed based on the PDEM; and (3) the critical chloride diffusion coefficient at a certain assurance rate can be obtained by the PDEM. The analysis results of this investigation will be valuable to the durability design for RAC.
\end{abstract}

Keywords: recycled aggregate concrete (RAC), recycled coarse aggregate (RCA), old attached mortar, chloride diffusion coefficient, probability density evolution method (PDEM).

\section{Abbreviations}

$A_{r a} \quad$ Area fraction of RCA

$A_{\text {oa }} \quad$ Area fraction of original (natural) aggregate in RCA

$A_{\text {om }} \quad$ Area fraction of old mortar in RCA

CDF Cumulative probability function

$D_{\text {RAC }} \quad$ Chloride diffusion coefficient of RAC

$D_{\text {om }} \quad$ Chloride diffusion coefficient of old attached mortar in RAC

$D_{n m} \quad$ Chloride diffusion coefficient of new mortar in RAC

$D_{o a} \quad$ Chloride diffusion coefficient of original aggregate

ITZ Interfacial transition zone

NAC Natural aggregate concrete

NCA Natural coarse aggregate

PDEM Probability density evolution method

PDF Probability density function

RAC Recycled aggregate concrete

RA Recycled aggregate

RCA Recycled coarse aggregate

$R_{\mathrm{RCA}} \quad$ RCA replacement ratio

$R_{r m} \quad$ Attached rate of old mortar or attached rate of residual mortar in RCA

\footnotetext{
${ }^{1)}$ College of Civil Engineering \& Architecture, Guangxi University, Nanning 530004, People's Republic of China.

${ }^{2)}$ Department of Structural Engineering, Tongji

University, Shanghai 200092, People's Republic of China.

*Corresponding Author; E-mail: jzx@tongji.edu.cn

Copyright $($ The Author(s) 2016. This article is published

with open access at Springerlink.com
}

\section{Introduction}

With a global intensification of the scarcity of resources in the twenty first century, the recycling of waste concrete is an important means for the implementation of a sustainable infrastructure development strategy. Compared with natural coarse aggregates (NCA), recycled coarse aggregates (RCA) have substantial characteristics in terms of uncertainties that arise from their complex composition (Wardeh et al. 2015). It is well-known that the properties of recycled aggregate concrete (RAC) are different from those of natural aggregate concrete (NAC) (Yehia et al. 2015; Wardeh et al. 2015). Previous theoretical analyses carried out in the framework of structural reliability theory and lab experiments have shown that: (1) higher scatter of the compressive strength of RAC affects the margins of structural safety (Breccolotti and Materazzi 2010); (2) the compressive strength of RAC varies with the RCA replacement percentage and it follows a normal probability distribution ( $\mathrm{Li}$ et al. 2006); and (3) the durability of RAC can be strongly affected by the porosity and the high water absorption of the RCA (Debieb et al. 2010; Kou and Poon 2006). It is necessary to well understand the properties of RCA in order to control the behaviour of RAC. Some hypothetical problems related to durability aspects have resulted in RCA being employed only as base filler for pavement construction (Muscalu et al. 2013; Vancura et al. 2009), thereby and unnecessarily limiting the scope of application of RCA. The durability of concrete is of great concern, especially in high-chloride environments such as coastal areas and where de-icing salt is used in cold 
regions, and so determining the chloride diffusion characteristics of concrete is required in order to control the durability of concrete structures (Morga and Marano 2015). Additionally, the effects of water to binder ratios and mineral admixtures on RAC chloride diffusion coefficient have already been discussed by Kou and Poon (Kou et al. 2007), this investigation will only focus on the physical and geometrical characteristics of RAC.

Similarly to NAC, chloride ions contained in the surrounding environment can penetrate $\mathrm{RAC}$, and thereafter induce corrosion of the embedded reinforcing steel bars. It is most important to quantify the chloride diffusion coefficient of RAC in order to better predict the initiation of corrosion (Care 2003). For the same volume of RAC, the diffusion coefficient of RAC increases with the content of old mortar (Xiao et al. 2012; Ying et al. 2013a). The application of RCA may increase the chloride penetration rate of RAC (Kou and Poon 2006; Kou et al. 2007). The chloride diffusivities of RAC generally increase with an increase of the RCA replacement ratio $\left(R_{r c a}\right)$; while for the same $R_{r c a}$, the chloride diffusivities and the distribution of the chloride concentration in the modelled RAC still differ due to the effect of different distributions and arrangements of RCA (Ying et al. 2013b).

Because the old attached mortar in RCA is the main difference between RCA and NCA, determining the diffusion coefficient of old attached mortar in RCA is needed to control the chloride diffusion coefficient of RAC. The old mortar in RCA is related to several indices of concrete durability. For example, the main properties of RAC that are affected unfavourably by the attached mortar content are its density, absorption and Los Angeles abrasion, as well as the correlations between them and the attached mortar content (Juan and Gutierrez 2009). RCA produced with only primary crushing have significantly higher water absorption when compared to that of NCA, due to the presence of significant amounts of attached mortar (Gokce et al. 2011). Many pioneering investigations have been undertaken to remove or reduce the residual mortar. For this purpose, Tam et al. (2007) attempted to reduce the mortar attached to RCA by three pre-soaking treatment approaches, namely ReMortar $(\mathrm{HCl})$, ReMortar (H2SO4) and ReMortar (H3PO4), while Abbas et al. (2007) proposed an equivalent mortar volume method to determine the residual mortar content of RCA. Furthermore, the old mortar stochastic distribution as well as its amount in RCA can be quantified by image analysis (Abbas et al. 2009). Therefore, it follows that the chloride diffusion coefficient of RAC has a stochastic distribution because of the stochastic distribution of old mortar in RCA (Abbas et al. 2009), and a stochastic servicelife model for chloride-induced corrosion in reinforced RAC have been developed and implemented well by Srubar (2015).

In this paper, the RAC is idealised as a three-phase material, containing new mortar, old mortar and natural aggregates. A three-phase composite chloride diffusion coefficient model of RAC is built to predict its chloride diffusion coefficient. The diffusion coefficient of the old mortar $\left(D_{o m}\right)$ and the adhesive rate of the old mortar $\left(R_{r m}\right)$ in RCA are taken as random variables. The probability density evolution method (PDEM) for the chloride diffusion coefficient analysis of RAC is then derived according to the three-phase composition material model. The advantage of this method is that the analytical probability density function (PDF) of RAC can be obtained, provided the probability distribution of the chloride diffusion coefficient of the old mortar and the content of the old mortar are known.

\section{Significance of the Research}

For the durability design of RAC, determining its chloride diffusion coefficient is essential. Due to the complexity and scatter of RAC at a mesoscopic scale, the probability distribution of chloride diffusion coefficient of RAC is needed to well understand. A probability density evolution method (PDEM) is developed in order to provide the foundation for a reliability analysis and a probabilistic approach for durability design of RAC structures.

\section{Probability Density Evolution Method for RAC}

\subsection{Chloride Diffusion Coefficient Model of RAC}

In analyzing the distribution of aggregate particles in concrete, it is usually assumed that aggregates in concrete, such as gravel, are spherical (Zheng and Li 2002). Based on the theoretical equations of Ying et al. (2013a), for Fuller aggregate gradation, the bigger the aggregate, the smaller is the volume fraction of ITZ around it. When the minimum diameter of aggregate is larger than $5 \mathrm{~mm}$, the volume fraction of ITZ will become very small, and the influence of ITZ on the chloride diffusion coefficient for RAC can be neglected. In fact, the diameter of recycled coarse aggregate is usually larger than $5 \mathrm{~mm}$. Therefore, in this investigation, it is assumed to take the recycled coarse aggregate concrete as a three-phase composite material: the new mortar, the old mortar and the natural aggregate. For simplicity, a two dimensional model is usually selected to study the chloride diffusion coefficient of concrete (Zheng et al. 2012). In this study, in order to verify old mortar distribution obtained from image analysis (Abbas et al. 2009), a two dimensional model will be constructed, see Fig. 1.

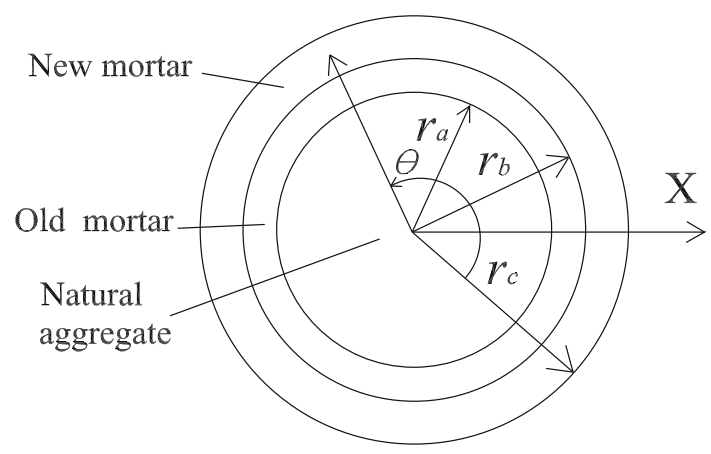

Fig. 1 Three-phase composite model of RAC. 
The dimension $r_{a}$ in Fig. 1 denotes the radius of the natural aggregate, $r_{b}-r_{a}$ is the thickness of the old mortar in RAC and $r_{c}-r_{b}$ is the thickness of the new mortar. To make the composite model be equivalent to that of a real concrete, $r_{a}, r_{b}$ and $r_{c}$ should satisfy the following relationships:

$$
\begin{aligned}
& \frac{r_{a}^{2}}{r_{c}^{2}}=A_{o a}, \\
& \frac{r_{b}^{2}}{r_{c}^{2}}=A_{o a}+A_{o m}=A_{r c a} \\
& \frac{A_{o m}}{A_{r c a}}=R_{r m}
\end{aligned}
$$

where $A_{o a}, A_{o m}$ and $A_{r c a}$ are the area fractions of the natural original aggregate, old mortar and recycled coarse aggregate, respectively; and $R_{\mathrm{rm}}$ is the old mortar adhesive rate.

The gradation of aggregate particles can be obtained from sieve particular analysis. Based on the theory of stereology (Zheng 2000), the probability density function for the spherical aggregates can be expressed by

$$
p(D)=\frac{n D_{\max }^{n} D_{\min }^{n}}{\left(D_{\max }^{n}-D_{\min }^{n}\right) D^{n+1}}
$$

where $D$ is the diameter of spherical aggregate particles, which varies within the minimum aggregate diameter $D_{\min }$ and the maximum aggregate diameter $D_{\max }$; and $n$ is a coefficient denoting the type of aggregate gradation. For the equal volume fraction (EVF) gradation, $n=3.0$, and for the Fuller gradation, $n=2.5$. The ITZ area fractions in normal concrete have been obtained based on aggregate gradation by Zheng and Zhou (2007). Similarly, the old mortar area fraction $\left(A_{\mathrm{om}}\right)$ in RAC can be derived as

$$
A_{o m}=1-A_{o a}-\left(1-A_{o a}\right) \exp \left[-\pi N_{A}\left(t_{1} h+t_{2} h^{2}\right)\right]
$$

where $N_{\mathrm{A}}$ is the number of recycled aggregate particles per unit area of concrete; $h$ is the thickness of old mortar; and $t_{1}$ and $t_{2}$ are the coefficients of $h$. According to Eqs. (2) and (3), it can get $A_{o a}=A_{R C A} \cdot\left(1-R_{r m}\right)$. According to Zheng and Zhou (2007), 2 $\left\langle R_{r c a}\right\rangle$ and $\pi\left\langle R_{r c a}^{2}\right\rangle$ represent average diameter and area of circular RCA in the concrete, and for $\operatorname{EVF}(n=3)$ and Fuller gradation $(n=2.5)$, there are

$$
\left\langle R_{r c a}^{2}\right\rangle= \begin{cases}\frac{D_{\min }^{2} D_{\max }^{2}\left(\ln D_{\max }-\ln D_{\min }\right)}{3\left(D_{\max }^{2}-D_{\min }^{2}\right)}, & \text { for } n=3 \\ \frac{3 \pi\left(D_{\min }^{1.5} D_{\max }^{2}-D_{\min }^{2} D_{\max }^{1.5}\right)}{16\left(D_{\max }^{1.5}-D_{\min }^{1.5}\right)}, & \text { for } n=2.5\end{cases}
$$

and

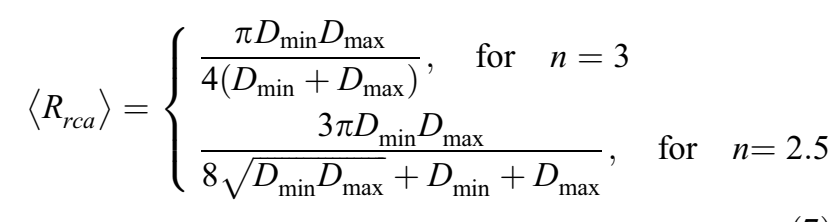

then $N_{\mathrm{A}}$ and $h$ can be expressed by

$$
\begin{aligned}
& N_{A}=\frac{A_{R C A}}{\pi\left\langle R_{r c a}^{2}\right\rangle} \\
& h=\left\langle R_{r c a}\right\rangle\left(1-\sqrt{R_{r m}}\right)
\end{aligned}
$$

and the coefficients $t_{1}$ and $t_{2}$ are respectively determined by

$$
\begin{aligned}
& t_{1}=\frac{2\left(\left\langle R_{r c a}\right\rangle \cdot \sqrt{R_{r m}}\right)}{1-A_{o a}} \\
& t_{2}=\frac{1}{1-A_{o a}}-\frac{A_{o a}}{\left(1-A_{o a}\right)^{2}}
\end{aligned}
$$

As a result, if the aggregate gradation, $D_{\min }, D_{\max }, A_{\text {rca }}$, and $R_{\mathrm{rm}}$ are given, the old mortar area fraction $A_{\mathrm{om}}$ can be determined from Eq. (5), and the area fraction of new mortar $A_{\text {nm }}$, can be simply determined as follows

$$
A_{n m}=1-A_{r c a}
$$

In deriving the chloride diffusion coefficient of RAC, let $D_{j}$ be the chloride diffusion coefficient of the original aggregate $(j=o a)$, old mortar $(j=o m)$, new mortar $(j=n m)$ and $\operatorname{RAC}(j=\mathrm{RAC})$, respectively. For steadystate diffusion questions, the chloride content in the homogeneous medium of the $j$ th phase constituent should satisfy the equation (Zheng and Zhou 2008):

$$
\nabla^{2} C_{j}(r, \theta)=0 \quad(j=o a, o m, n m)
$$

where $\nabla^{2}()$ is the Laplacian operator in polar coordinates, i.e.,

$$
\nabla^{2}()=\frac{\partial^{2}()}{\partial r^{2}}+\frac{1}{r} \cdot \frac{\partial()}{\partial r}+\frac{1}{r^{2}} \cdot \frac{\partial^{2}()}{\partial \theta^{2}}
$$

Since the aggregate is relatively impermeable when compared with the new mortar and old mortar, this study assumes that $D_{o a}=0$. Thus, the radial chloride flux at the om - oa interface $\left(r=r_{o a}\right)$ vanishes, i.e.

$$
q_{\text {oa }}\left(r_{a}, \theta\right)=0
$$

To determine the chloride diffusion coefficient of the concrete, the radial chloride flux $q_{n m}(r, \theta)$ at the outer boundary of the composite circle $\left(r=r_{c}\right)$ is specified by

$$
q_{n m}\left(r_{c}, \theta\right)=\bar{q} \cos \theta
$$

where $\bar{q}$ is a constant. As a result, the governing Eq. (13) with the boundary conditions given by Eqs. (15) and (16) forms a complete and well-posed boundary value problem. From the boundary conditions in Eqs. (15) and (16), it is evident that the solution to Eq. (13) is

$$
C_{j}(r, \theta)=\left(A_{j 1} r+\frac{A_{j 2}}{r}\right) \cos \theta \quad(j=o m, n m)
$$


where $A_{j 1}$ and $A j 2(j=o m, n m)$ are coefficients. The corresponding radial chloride flux $q_{j}(r, \theta)$ is given by

$$
q_{j}(r, \theta)=-D_{j}\left(A_{j 1}-\frac{A_{j 2}}{r^{2}}\right) \cos \theta \quad(j=o m, n m)
$$

Substituting Eq. (18) into Eqs. (15) and (16) then yields

$$
\begin{aligned}
& A_{o m 1}-\frac{A_{o m 2}}{r_{a}^{2}}=0 \\
& A_{n m 1}-\frac{A_{n m 2}}{r_{c}^{2}}=-\frac{\bar{q}}{D_{n m}}
\end{aligned}
$$

Considering the continuity conditions of the chloride content and the radial chloride flux at $r=r_{b}$,

$$
\begin{aligned}
& A_{o m 1} r_{b}+\frac{A_{o m 2}}{r_{b}}=A_{n m 1} r_{b}+\frac{A_{n m 2}}{r_{b}} \\
& D_{o m}\left(A_{o m 1}-\frac{A_{o m 2}}{r_{b}^{2}}\right)=D_{n m}\left(A_{n m 1}-\frac{A_{n m 2}}{r_{b}^{2}}\right)
\end{aligned}
$$

the above two equations can be obtained. In order to eliminate the influence of circumstantial diffusion, the chloride content at the outer boundary at $r=r_{c}$ is expressed by

$$
C_{n m}\left(r_{c}, \theta\right)=\bar{c} \cos \theta
$$

or

$$
A_{n m 1} r_{c}+\frac{A_{n m 2}}{r_{c}}=\bar{c}
$$

The relationship between $\bar{q}$ and $\bar{c}$ can be obtained by eliminating $A_{o m 1}, A_{o m 2}, A_{n m 1}, A_{n m 2}, r_{a}, r_{b}, r_{c}$, from Eqs. (1), (2) and (19) to (24) as

$$
\begin{aligned}
& D_{\mathrm{RAC}}=D_{n m} \\
& -\frac{2\left[2 A_{o a}+(1-q) A_{o m}\right] D_{n m}}{1+q+(1-q) A_{o a}\left(A_{o a}+A_{o m}\right)^{-1}+2 A_{o a}+(1-q) A_{o m}}
\end{aligned}
$$

The aggregate area fraction $A_{r a}$ and the adhesive rate of residual mortar $R_{r m}$ are usually the most important parameters influencing the properties of RAC when the aggregate gradation is known (Poon et al. 2004). By defining the terms

$$
\begin{aligned}
& R_{r m}=\frac{A_{o m}}{A_{o m}+A_{o a}} \\
& A_{r a}=A_{o m}+A_{o a}
\end{aligned}
$$

Eq. (28) can then be converted to

$$
D_{\mathrm{RAC}}=u\left(A_{r a}, R_{r m}, D_{n m}, D_{o m}\right) / v\left(A_{r a}, R_{r m}, D_{n m}, D_{o m}\right)
$$

where the variables

$$
u=-D_{n m}\left[D_{n m}\left(R_{r m}-2\right)\left(A_{r a}-1\right)+R_{r m} D_{o m}\left(A_{r a}+1\right)\right]
$$

and

$$
v=D_{n m}\left(R_{r m}-2\right)\left(A_{r a}+1\right)+R_{r m} D_{o m}\left(A_{r a}-1\right)
$$

\subsection{Probability Density Evolution Method for RAC}

Many pioneering investigators have studied the random distribution of $R_{r m}$ (Abbas et al. 2009) and the chloride diffusion coefficient of conventional concrete (Zhang et al. 2011).

$$
\bar{q}=-\left\{D_{n m}-\frac{2\left[2 A_{o a}+(1-q) A_{o m}\right] D_{n m}}{1+q+(1-q) A_{o a}\left(A_{o a}+A_{o m}\right)^{-1}+2 A_{o a}+(1-q) A_{o m}}\right\}\left(\frac{\bar{c}}{r_{c}}\right)
$$

where

$$
q=\frac{D_{o m}}{D_{n m}}
$$

On the other hand, if the composite circle of RAC is considered as a monolithic homogeneous medium with a chloride diffusion coefficient $D_{\mathrm{RAC}}$, it can be easily shown that $\bar{q}$ is related to $\bar{c}$ (Eq. (23)) by

$$
\bar{q}=-D_{\mathrm{RAC}}\left(\frac{\bar{c}}{r_{c}}\right)
$$

Finally, the chloride diffusion coefficient of RAC can be determined by comparing Eq. (25) with Eq. (27), giving
However, the probabilistic information for $D_{\mathrm{RAC}}$ is difficult to capture and quantify, and this has continued to be a difficult task for researchers. The following method may be used to obtain the probability distribution of $D_{\mathrm{RAC}}$ based on the probability density evolution method (PDEM).

In Eq. (31), suppose that $A_{r a}$ and $D_{n m}$ are constants and that $0<R_{r m} \leq 1,1 \times 10^{-6} \mathrm{~mm}^{2} / \mathrm{s}<D_{o m} \leq 15 \times 10^{-6}$ $\mathrm{mm}^{2} / \mathrm{s}$, and suppose that $R_{r m}$ and $D_{o m}$ are continuous independent random variables, which follow the general probability density functions (PDFs) $f_{R_{r m}}\left(R_{r m}\right)$ and $f_{D_{o m}}\left(D_{o m}\right)$ respectively. In accordance with elementary probability theory (Walpole et al. 2011), the joint PDF is

$$
f_{R_{r m}, D_{o m}}\left(R_{r m}, D_{o m}\right)=f_{R_{r m}}\left(R_{r m}\right) \cdot f_{D_{o m}}\left(D_{o m}\right)
$$


It can be easily proved that the mappings $U=u\left(R_{r m}, D_{o m}\right)$ and $V=v\left(R_{r m}, D_{o m}\right)$ define a one-to-one transformation between the points $\left(R_{r m}, D_{o m}\right)$ and $(u, v)$, so Eqs. (32) and (33) may be uniquely solved for $D_{o m}$ and $R_{r m}$ in terms of $u$ and $v$, and are given by

$$
\begin{aligned}
& R_{r m}(u, v)=\frac{1}{4} \frac{D_{n m} A_{r a} v+8 D_{n m}^{2} A_{r a}+D_{n m} v-u+u A_{r a}}{D_{n m}^{2} A_{r a}} \\
& D_{o m}(u, v)=-\frac{D_{n m}\left(D_{n m} A_{r a} v+u A_{r a}-D_{n m} v+u\right)}{D_{n m} A_{r a} v+8 D_{n m}^{2} A_{r a}+D_{n m} v-u+u A_{r a}}
\end{aligned}
$$

According to Walpole et al. (2011), the combined probability distribution of $U$ and $V$ is

$$
f_{U, V}(u, v)=f_{R_{r m}, D_{o m}}\left[R_{r m}(u, v), D_{o m}(u, v)\right]\left|\mathbf{J}_{R_{r m}, D_{o m}}\right|
$$

where the Jacobian is a $2 \times 2$ matrix:

$$
\mathbf{J}_{R_{r m}, D_{o m}}=\left[\begin{array}{cc}
\frac{\partial R_{r m}}{\partial u} & \frac{\partial R_{r m}}{\partial v} \\
\frac{\partial D_{o m}}{\partial u} & \frac{\partial D_{o m}}{\partial v}
\end{array}\right]
$$

Similarly, if $R_{r m}$ is a constant and $D_{o m}$ is a random variable, the PDF of $D_{\mathrm{RAC}}$ with the random variable $D_{o m}$ can be written as

$$
f_{D_{o m}}\left(D_{\mathrm{RAC}}\right)=f_{D_{o m}}\left[D_{o m}\left(D_{\mathrm{RAC}}\right)\right]\left|\mathbf{J}_{D_{o m}}\right|
$$

where

$$
\begin{aligned}
& D_{o m}\left(D_{\mathrm{RAC}}\right) \\
& =-\frac{D_{n m}\left(R_{r m}-2\right)\left[\left(-1+A_{r a}\right) D_{n m}+\left(A_{r a}+1\right) D_{\mathrm{RAC}}\right]}{\left[\left(A_{r a}+1\right) D_{n m}+D_{\mathrm{RAC}}\left(-1+A_{r a}\right)\right] R_{r m}}
\end{aligned}
$$

and the Jacobian

$$
\mathbf{J}_{D_{o m}}=\frac{\partial D_{o m}\left(D_{\mathrm{RAC}}\right)}{\partial D_{\mathrm{RAC}}}
$$

The approach proposed above, which is one- and twodimensional instead of being multi-dimensional, can be formulated and solved to produce the probability density evolution (PDF) of the random variable $D_{\mathrm{RAC}}$, which is termed as the probability density evolution method (PDEM).

Eq. (37) can also be expanded as

$$
f_{U, V}(u, v)=\frac{f_{R_{r m}}\left(\frac{8 D_{n m}^{2} A_{r a}+v\left(A_{r a}+1\right) D_{n m}+\left(A_{r a}-1\right) u}{4 D_{n m}^{2} A_{r a}}\right) f_{D_{o m}}\left(-\frac{\left[v\left(A_{r a}-1\right) D_{n m}+\left(A_{r a}+1\right) u\right] D_{n m}}{8 D_{n m}^{2} A_{r a}+v\left(A_{r a}+1\right) D_{n m}+\left(A_{r a}-1\right) u}\right)}{\left|\left(D_{n m} v+8 D_{n m}^{2}+u\right) A_{r a}+D_{n m} v-u\right|}
$$

Using elementary probability theory (Walpole et al. 2011), the PDF of $D_{\mathrm{RAC}}$ with the random variables $R_{r m}$ and $D_{o m}$ can then be written as

$$
f_{U / V}\left(D_{\mathrm{RAC}}\right)=\int_{\min \left[\mathrm{v}\left(\mathrm{R}_{r m}, \mathrm{D}_{o m}\right)\right]}^{\max \left[\mathrm{v}\left(\mathrm{R}_{r m}, \mathrm{D}_{o m}\right)\right]}|v| f_{V, U}\left(v, v D_{\mathrm{RAC}}\right) \mathrm{d} v
$$

Specifically, if $D_{o m}$ is a constant and $R_{r m}$ is a random variable, the PDF of $D_{\mathrm{RAC}}$ with the random variable $R_{r m}$ can be written as

$$
f_{R_{r m}}\left(D_{\mathrm{RAC}}\right)=f_{R_{r m}}\left[R_{r m}\left(D_{\mathrm{RAC}}\right)\right]\left|\mathbf{J}_{R_{r m}}\right|
$$

where

$$
\begin{aligned}
& R_{r m}\left(D_{\mathrm{RAC}}\right)= \\
& \frac{2\left[\left(-1+A_{r a}\right) D_{n m}+D_{\mathrm{RAC}}\left(A_{r a}+1\right)\right] D_{n m}}{\left(-1+A_{r a}\right) D_{n m}^{2}+\left(D_{o m}+D_{\mathrm{RAC}}\right)\left(A_{r a}+1\right) D_{n m}+D_{R A C} D_{o m}\left(-1+A_{r a}\right)}
\end{aligned}
$$

and the Jacobian

$$
\mathbf{J}_{R_{r m}}=\frac{\partial R_{r m}\left(D_{\mathrm{RAC}}\right)}{\partial D_{\mathrm{RAC}}}
$$

\subsection{Calibration for Probability Distribution of Old Attached Mortar Content}

The general method to evaluate the PDF of chloride diffusion coefficient of RAC due to variation of the old attached mortar in RCA was successfully derived in last section, therefore, the PDF of old attached mortar needs to be determined in advance. A number of researchers (Tam and Tam 2007; Abbas et al. 2009) have investigated the content of old adhesive mortar in RCA. Abbas et al. (2009) investigated the distribution of the residual mortar content of RCA by the method of image analysis, which served as a quality control tool for such aggregates and which provided an accurate measurement of the residual mortar content in recycled aggregates. The average frequency of the RCA particles corresponds to four types of residual mortar distribution: A [RCA-MO (4.75-9.5 mm fraction)]; B [RCAVA (4.75-9.5 mm fraction)]; C [RCA-VA (9.5-12.7 mm fraction)] and D [RCA-VA (12.7-19 mm fraction)]. RCA$\mathrm{MO}$ and RCA-VA mean the RCA from Montreal and Vancouver, respectively. The residual mortar content is the weight-based $R_{r m w}$, while the residual mortar content in the current paper is the area-based $R_{r m}$, with the relationship between them being 


$$
R_{r m w}=\frac{G_{o m} R_{r m}}{\left(G_{o a}-G_{o m}\right) R_{r m}-G_{o a}}
$$

where $\mathrm{G}_{o m}$ and $\mathrm{G}_{o a}$ are the relative densities (specific gravities) of old mortar and original aggregates, respectively.

After converting the histogram of $R_{r m w}$ into the histogram of $R_{r m}$ by using Eq. (47), the probability density values of $R_{r m}$ can be calculated (Walpole et al. 2011). The equations of Weibull and Chi squared distribution are shown in Eq. (48) and Eq. (49) Substitution of $x$ with $R_{r m}$ in the following two definitions is used to fit the probability density values of $R_{r m}$ with the data $\mathrm{A}, \mathrm{B}, \mathrm{C}, \mathrm{D}$, respectively, producing the results displayed in Fig. 2. There is some scatter for $R_{r m}$ distribution because that recycled coarse aggregates from two sources representing totally different geographical locations and geological environments (Abbas et al. 2009).

$$
\begin{aligned}
& \text { Weibull }(x \mid a, b)=\left\{\begin{array}{cc}
0 & x<0 \\
\frac{b x^{-1}+b e^{-\left(\frac{x}{a}\right)^{b}}}{a^{b}} & \text { otherwise }
\end{array}\right. \\
& \text { Chi-squared }(x \mid v)=\left\{\begin{array}{cc}
0 & x<0 \\
\frac{x^{\frac{1}{2} v-1} e^{-\frac{1}{2} x}}{2^{\frac{1}{2}} \Gamma\left(\frac{1}{2} v\right)} & \text { otherwise }
\end{array}\right.
\end{aligned}
$$

It can be seen from these figures that, except for the data with relative large $R_{r m}$, the data fits well with the PDF. The variation of the PDF with $R_{r m}$ can be divided into three stages: (i) the PDF of $R_{r m}$ decreases sharply with an increase of $R_{r m}$ when $R_{r m}$ is less than 0.2 ; (ii) the PDF of $R_{r m}$ decreases slowly with an increase of $R_{r m}$ when $R_{r m}$ is between 0.2 and 0.95 ; and (iii) the PDF of $R_{r m}$ increases with an increase of $R_{r m}$ when $R_{r m}$ is beyond about 0.95 . The reason for this may be that the smaller the aggregate size, the more difficult the old mortar is removed during crushing process. In some experiments (Xiao et al. 2014), the recycled aggregate was sieved by using an iron sieve with the side size of $10 \mathrm{~mm}$, then the recycled aggregate sieved was defined as continuous gradation according to aggregate gradation curves, which satisfy the standard for technical requirements and test method of sand and crushed stone (or gravel) for ordinary concrete. Therefore, if recycled aggregates are sieved to some extent, the variation tendency of the PDF with $R_{\mathrm{rm}}$ only has the first two stages, i.e., decreasing trend totally. As a result, the Weibull function and Chi Square function are suitable for describing the probability density distribution of $R_{\mathrm{rm}}$.

\subsection{Experimental Verification}

Ordinary Portland cement with a 28-day compressive strength of $42.5 \mathrm{MPa}$ was selected in this experimental study. The fine aggregate was river sand. Recycled coarse

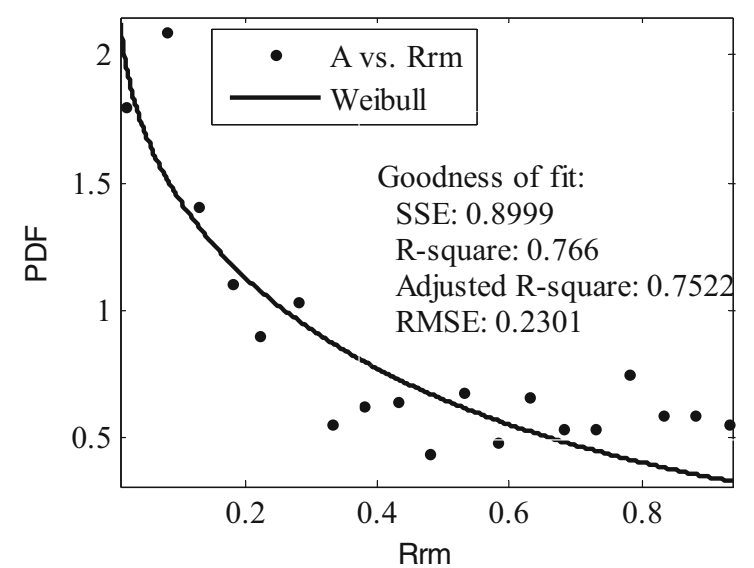

a PDF with data A

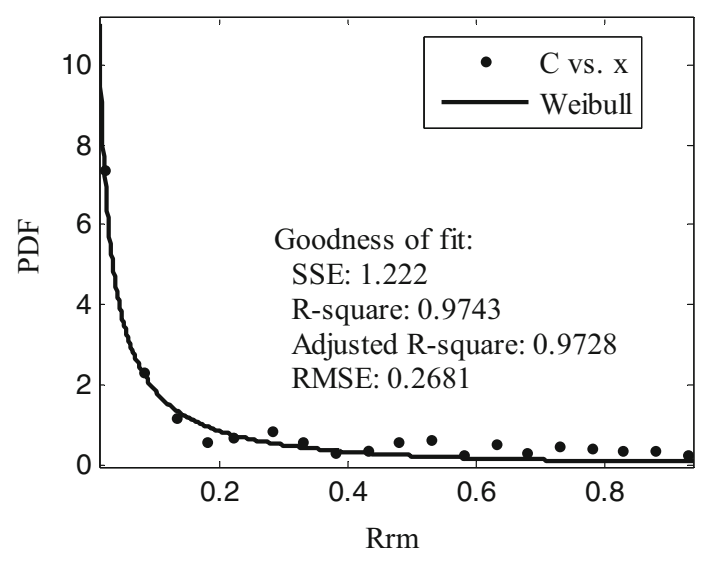

c PDF with data $\mathrm{C}$

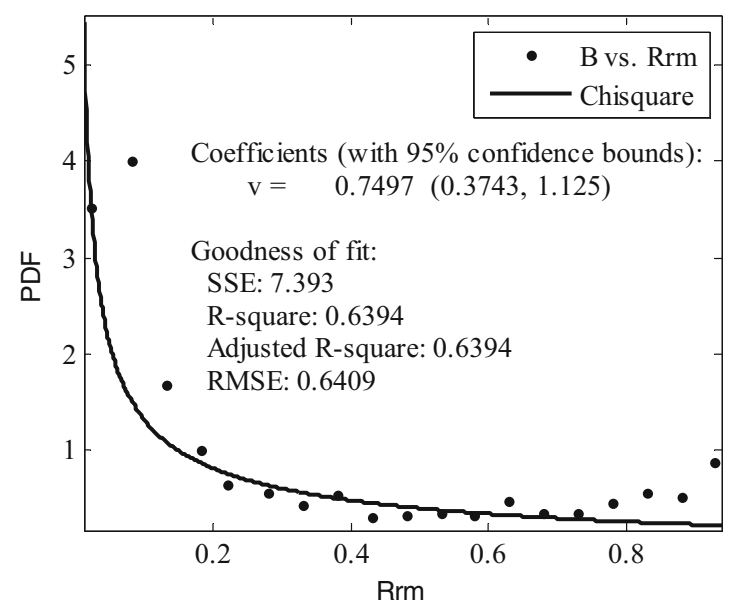

b PDF with data B

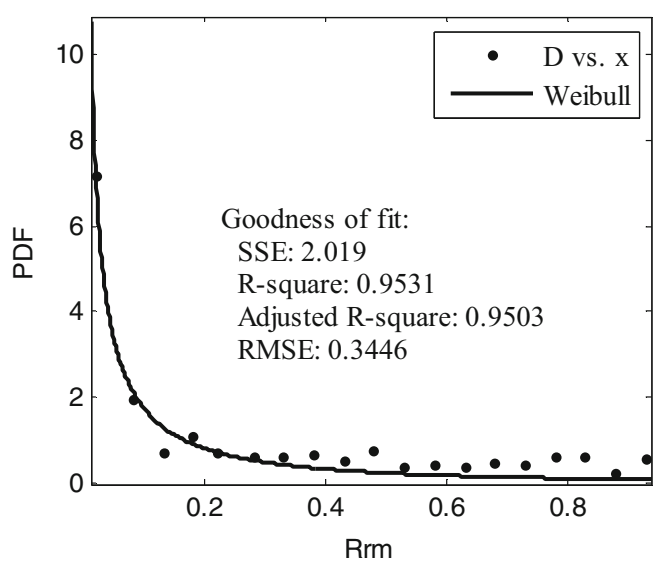

d PDF with data D

Fig. 2 PDF value and fitting functions. 
Table 1 The properties of the coarse aggregate.

\begin{tabular}{c|c|c|c|c|c|c}
\hline Types & Size $(\mathrm{mm})$ & $\begin{array}{c}\text { Crushing } \\
\text { index }(\%)\end{array}$ & $\begin{array}{c}\text { Bulk density } \\
\left(\mathrm{kg} / \mathrm{m}^{3}\right)\end{array}$ & $\begin{array}{c}\text { Apparent density } \\
\left(\mathrm{kg} / \mathrm{m}^{3}\right)\end{array}$ & $\begin{array}{c}\text { Water absorption } \\
(\%)\end{array}$ & $\begin{array}{c}\text { Silt content (\%) } \\
\text { RCA }\end{array}$ \\
\hline \hline NCA & $25-31.5$ & 24 & 1280 & 2500 & 6 & 0.5 \\
\hline
\end{tabular}

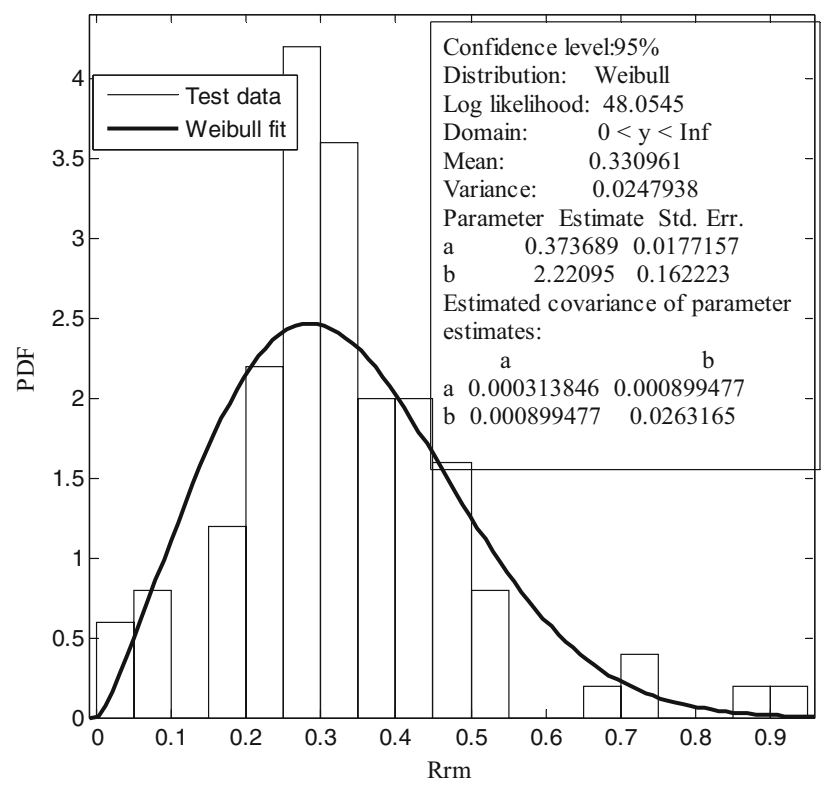

Fig. 3 The probable density distribution of old mortar adhesive rate.

aggregate (RCA) was obtained from concrete waste with original strength grade of C30. According to JGJ 52-2006, the physical properties of the NCA and the RCA are listed in Table 1.

Given the apparent density of mortar, original natural aggregate and recycled aggregate, the old mortar adhesive rate $\left(R_{r m}\right)$ of RCA can be calculated by equations in Ref. (Ying et al. 2013a), after 100 tests, the probably density distribution and distribution function of old mortar adhesive rate of RCA is calculated by Statistics Toolbox in software MATLAB, see Fig. 3.

The mixture proportions for the NAC, RAC and mortar in this test are presented in Table 2. The volume fraction of coarse aggregate is $40 \%$, and the area fraction of coarse aggregate is $54 \%$ for a section of concrete according to composited spherical model of RAC. The preparation and curing of the mix were conducted in the laboratory of Guangxi University in Nanning, PR China. Two-stage mixing approach was used to cast recycled concrete. The mixture was cast in more than thirty $\Phi 103 \mathrm{~mm} \times 300 \mathrm{~mm}$ PVC tubes and thirty $100 \times 100 \times 100 \mathrm{~mm}$-cube moulds. All were compacted on a vibration table, the PVC end cap and plastic film were used to prevent evaporation, see Fig. 4, then demoulded a day after casting and water-cured in a standard curing room for 28 days. Each cylindrical concrete sample was cut to five pieces, and only three pieces located in the middle of the tube were used to chloride diffusion coefficient test by the rapid chloride test method (RCM), see Fig. 5, according to Standard for test methods of long-term performance and durability of ordinary concrete. Sixty chloride diffusion coefficients with series I, thirty for series II and three for series III were obtained by RCM test, and the probability density distribution of data with series I is calculated by the Statistics Toolbox in software MATLAB, see Fig. 6. The mean value of chloride diffusion coefficient of new mortar is $3 \times 10^{-6} \mathrm{~mm}^{2} / \mathrm{s}$ by RCM test. It is assumed that the chloride diffusion coefficient of natural aggregate is zero (Ying et al. 2013a), then the chloride diffusion coefficient of old mortar $\left(D_{o m}\right)$ can be calculated as $10 \times 10^{-6} \mathrm{~mm}^{2} / \mathrm{s}$ by comparing value in series I and series II according to composited spherical model (Ying et al. 2013a). Given the information above, the probability distribution of $D_{\text {RAC }}$ can be calculated by PDEM, as shown in Fig. 6 .

It can be illustrated from Fig. 6 that, the probable density distribution of RAC by PDEM is similar to that by RCM test although there is some difference. The mean value by RCM test is a little larger than that by PDEM, the reason may be that the ITZ is not considered in this study, the influence ITZ of RCA on the $D_{\mathrm{RAC}}$ can be ignored when the partial size is larger than $5 \mathrm{~mm}$ (Ying et al. 2013a). Therefore, the PDEM can be verified to calculate the probable distribution of chloride diffusion coefficient of RAC.

\subsection{Parametric Analysis}

To analyse the effect of attached old mortar on $D_{\mathrm{RAC}}$, the following three aspects should be addressed. The first aspect involves a sensitivity analysis of the effects of $D_{o m}$ and $R_{r m}$ on $D_{\text {RAC }}$; the second aspect analyses the verification of PDEM with Monte Carlo method; and the third part is an analysis of the effect of both $R_{r m}$ and $D_{o m}$ on $D_{\text {RAC }}$ using the PDEM. It should be noted that, this study emphasizes on

Table 2 Mix proportion by mass.

\begin{tabular}{c|c|c|c|c|c|c}
\hline Series & Portland cement & Water & Fine aggregate & RCA & NCA & $\begin{array}{c}\text { Polycarboxylate } \\
\text { superplasticizer (\%) }\end{array}$ \\
\hline \hline I & 1 & 0.4 & 1.44 & 2.17 & 0.3 \\
\hline II & 1 & 0.4 & 1.44 & & 2.34 & 0.3 \\
\hline III & 1 & 0.4 & 1.44 & & & \\
\hline
\end{tabular}




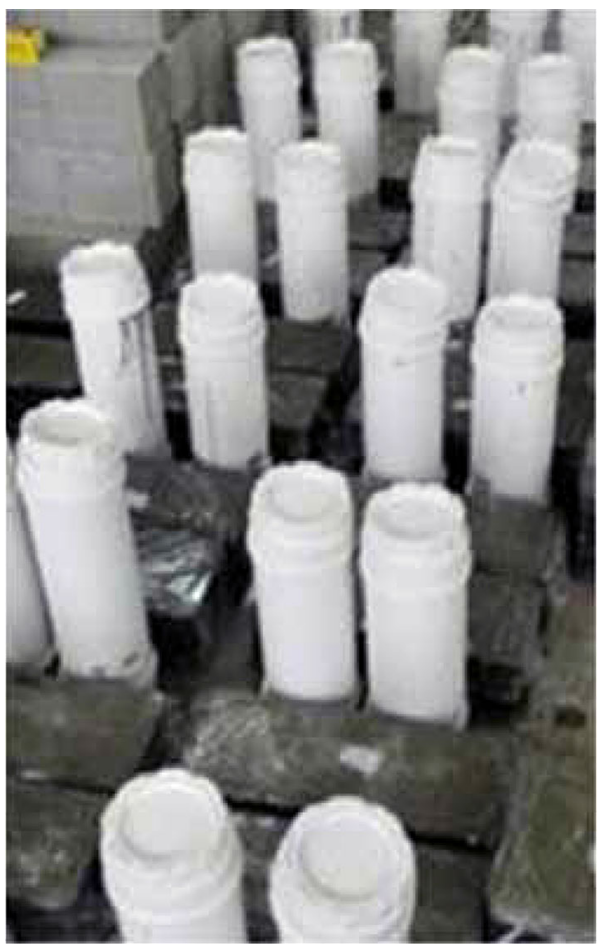

Fig. 4 Cylindrical and cube specimens.

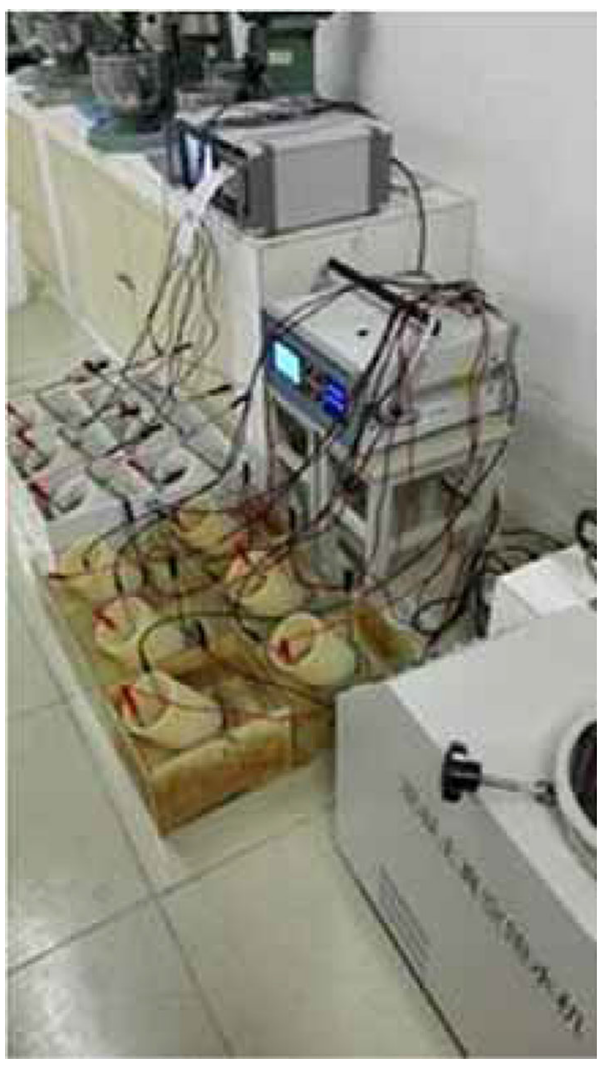

Fig. 5 Rapid chloride diffusion coefficient test.

effects of the random of old attached mortar on the random of chloride diffusion coefficient of RAC, therefore, effects of recycled aggregate contents and particle size distribution on chloride diffusion coefficient have not been discussed in the following analysis.

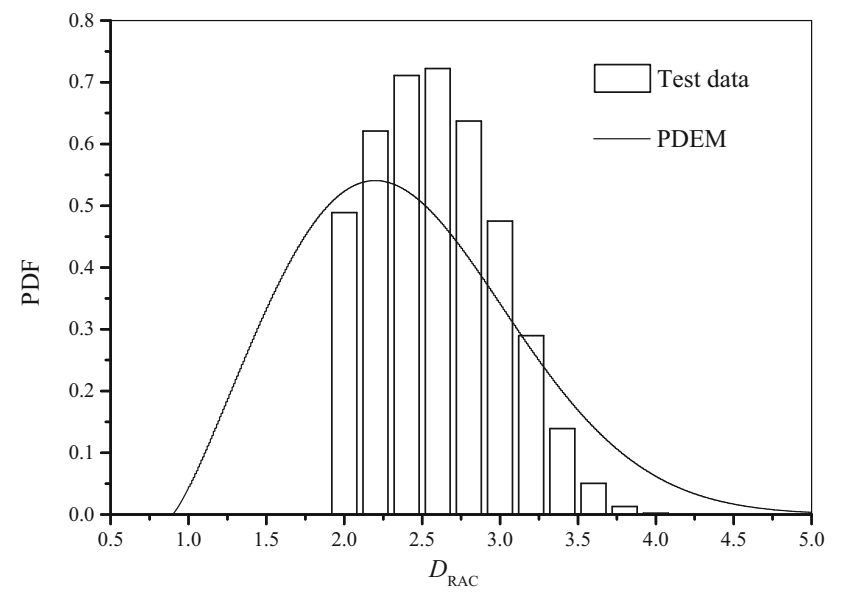

Fig. 6 Probable density distribution of $D_{\mathrm{RAC}}\left(\times 10^{-6} \mathrm{~mm}^{2} / \mathrm{s}\right)$.

\subsubsection{Sensitivity Analysis}

To investigate the effect of $D_{\text {om }}$ on the chloride diffusion coefficient of concrete, according to the parameter assignment given by Zheng and Zhou (2008) and Xiao et al. (2012), it is assumed that $D_{n m}=2\left(\times 10^{-6} \mathrm{~mm}^{2} / \mathrm{s}\right), R_{r m}=0.3$, and let $D_{o m}=3,6,9\left(\times 10^{-6} \mathrm{~mm}^{2} / \mathrm{s}\right)$. With these parameters, the chloride diffusion coefficient of concrete can be determined from Eq. (31). The results are shown in Fig. 7.

As expected in Fig. 7a, $D_{\mathrm{RAC}}$ varies with an increase of $A_{r a}$ for $D_{o m}=3,6,9\left(\times 10^{-6} \mathrm{~mm}^{2} / \mathrm{s}\right)$. The chloride diffusion coefficient of the concrete increases with an increase of $D_{\text {om }}$ for a given $A_{r a}$. When $D_{o m}$ increases from 3 to $9\left(\times 10^{-6} \mathrm{~mm}^{2} /\right.$ s), $D_{\mathrm{RAC}}$ increases by 21,47 , and $80 \%$ for $A_{r a}$ values of 0.2 , 0.4 , and 0.6 , respectively. The reason for this increase is that the aggregate is impermeable as assumed in this study, and the old mortar is more permeable than the new mortar. This implies that the chloride diffusion coefficient of old mortar can affect the chloride diffusion coefficient of concrete.

Setting $D_{n m}=2\left(\times 10^{-6} \mathrm{~mm}^{2} / \mathrm{s}\right), D_{o m}=6\left(\times 10^{-6} \mathrm{~mm}^{2} / \mathrm{s}\right)$ and $R_{r m}=0,0.3,0.5$, and 0.7 produces the results in Fig. $7 \mathrm{~b}$. It can be seen from Fig. $7 \mathrm{~b}$ that $D_{\mathrm{RAC}}$ decreases with an increase of $A_{r a}$ for $R_{r m}=0,0.3$, and increases with an increase of $A_{r a}$ for $R_{r m}=0.7$. The value of $D_{\mathrm{RAC}}$ increases with an increase of the $R_{r m}$ for a given $A_{r a}$. When $R_{r m}$ increases from 0 to $0.5, D_{\mathrm{RAC}}$ increases by 50,133 , and $300 \%$ for $A_{r a}$ values of $0.2,0.4$, and 0.6 , respectively. Furthermore, the influence of $R_{r m}$ on $D_{\mathrm{RAC}}$ seems more obvious than that of $D_{o m}$ according to comparisons between Fig. 7a, b. The reason may be that the variation rang of $D_{o m}$ is generally smaller than that of $R_{r m}$. The improvement of $R_{r m}$ can increase the old mortar content and decrease the original aggregate content simultaneously for a given $A_{r a}$. The value of $R_{r m}$ may be more sensitive to $D_{\mathrm{RAC}}$ than that of $D_{o m}$.

Therefore, in order to reduce the chloride diffusion coefficient of RAC, $D_{o m}$ and $R_{r m}$ need to be decreased by reducing the water/binder ratio and using pre-soaking approaches (Tam and Tam 2007), carbonizing recycled aggregate (Kou et al. 2014), and triple mixing method (Kong et al. 2010). 


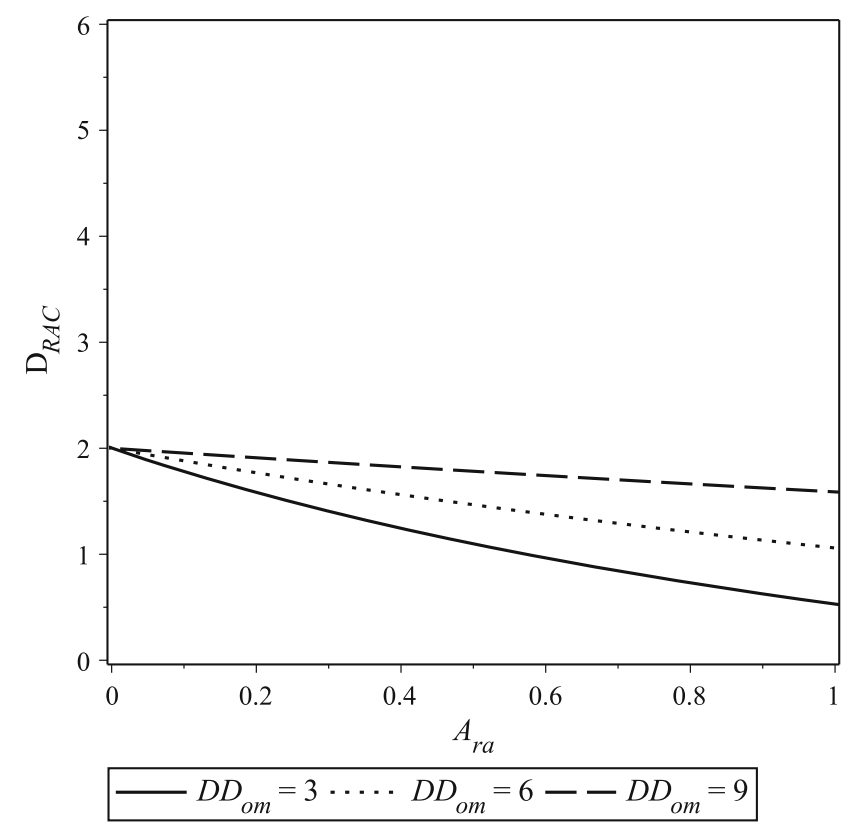

a Variation of $D_{\mathrm{RAC}}$ with $R_{r m}$

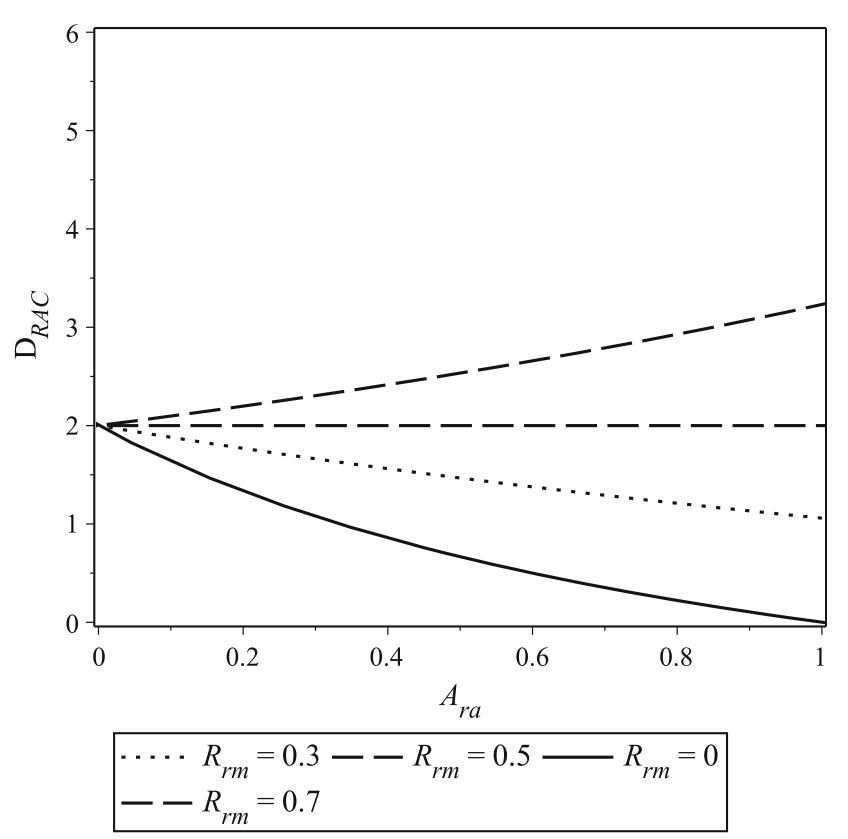

b Variation of $D_{\mathrm{RAC}}$ with $D_{\text {om }}$

Fig. 7 Variation of $D_{\mathrm{RAC}}\left(\times 10^{-6} \mathrm{~mm}^{2} / \mathrm{s}\right)$.

\subsubsection{Comparison of PDEM with Monte Carlo} Method

Monte Carlo method is often used to simulate chloride diffusion in concrete and has been verified by some experiments (Tikalsky et al. 2005). In order to compare PDEM with Monte Carlo method, according to analysis in last section, it is supposed that old mortar content obey Weibull $\left(R_{r m} \mid 0.6542,0.9189\right)$, and chloride diffusion coefficient of old mortar obey Normal $\left(D_{o m} \mid 7,1\right) .1000$ random numbers are used for the distribution, see Fig. 8. Let $D_{n m}=2$ $\left(\times 10^{-6} \mathrm{~mm}^{2} / \mathrm{s}\right), D_{o m}=6\left(\times 10^{-6} \mathrm{~mm}^{2} / \mathrm{s}\right)$ and $A_{r a}=9 / 64 \pi$; and $R_{r m}$ follow the distributions in Fig. 8a. With these inputs, the PDF of $D_{\mathrm{RAC}}$ can be calculated according to Eqs. (31)-(33), as displayed in Fig. 9a. Let $D_{n m}=2$ ( $\left.\times 10^{-6} \mathrm{~mm}^{2} / \mathrm{s}\right), A_{r a}=9 / 64 \pi ; R_{r m}$ follow the distributions in Fig. 8a, and $D_{o m}$ follow the distributions in Fig. 8b. With these inputs, the PDF of $D_{\text {RAC }}$ can be calculated according to Eqs. (31)-(33), as displayed in Fig. 9b.

It can be seen from Fig. 9 that, the chloride diffusion coefficient of RAC calculated by PDEM is in accordance with that by Monte Carlo method.

\subsubsection{PDEM for $D_{\text {RAC }}$ with Variable $R_{r m}$ and $D_{o m}$}

In many cases, the source of recycled coarse aggregates is uncertain. For example, some RCA came from buildings while some came from concrete pavements. Even for the same building, the quality of the concrete was different in different parts. Different types of waste concrete were usually collected together to produce recycled coarse aggregates, and the quality of old mortar in recycled aggregates is of course variable. The chloride diffusion coefficient of old mortar in RCA is also highly variable for different aggregates. The chloride diffusion coefficient of old mortar in RCA may follow a certain probability distribution.
In this study, the influence of old mortar in RCA on the chloride diffusion coefficient of RAC is focused on. For this reason, a modelled RAC that contains only one coarse aggregate is selected. Some researchers have investigated the probability distribution of the chloride diffusion coefficient of natural aggregate concrete (Zhang et al. 2011). However, the probability distribution of the diffusion coefficient of old mortar in RAC appears not to have been reported in literature. Therefore, the probability distribution functions of the chloride diffusion coefficient of conventional concrete are assumed to be similar to those of old mortar in recycled aggregates. According to Zhang et al. (2011), $D_{o m}$ is assumed to follow Weibull and Normal distributions.

The cumulative probability functions (CDF) of $R_{r m}$ and $D_{o m}$ should satisfy

$$
\int_{\min (\mathrm{x})}^{\max (\mathrm{x})} f(x) \mathrm{d} x=1
$$

and therefore, the updated PDFs of $R_{r m}$ and $D_{o m}$ are given by

$$
f_{R_{r m}}\left(R_{r m}\right)=\frac{\bar{f}_{R_{r m}}\left(R_{r m}\right)}{\int_{\min \left(\mathrm{R}_{\mathrm{rm}}\right)}^{\max \left(\mathrm{R}_{\mathrm{m}}\right)} \bar{f}_{R_{r m}}\left(R_{r m}\right) \mathrm{d} R_{r m}}
$$

and

$$
f_{D_{o m}}\left(D_{o m}\right)=\frac{\bar{f}_{D_{o m}}\left(D_{o m}\right)}{\int_{\min \left(\mathrm{D}_{o m}\right)}^{\max \left(\mathrm{D}_{o m}\right)} \bar{f}_{D_{o m}}\left(D_{o m}\right) \mathrm{d} D_{o m}}
$$

where $R_{r m}$ and $D_{o m}$ are in the range of $0<R_{r m} \leq 1$ and 1 $\left(\times 10^{-6} \mathrm{~mm}^{2} / \mathrm{s}\right)<D_{\text {om }} \leq 15\left(\times 10^{-6} \mathrm{~mm}^{2} / \mathrm{s}\right)$.

To compare the effects of the PDF of $R_{r m}$ and $D_{o m}$ on the PDF of $D_{\mathrm{RAC}}$, the distributions of $R_{r m}$ and $D_{o m}$ are listed in Table 3, in which A-W denotes the combination of the PDFs 


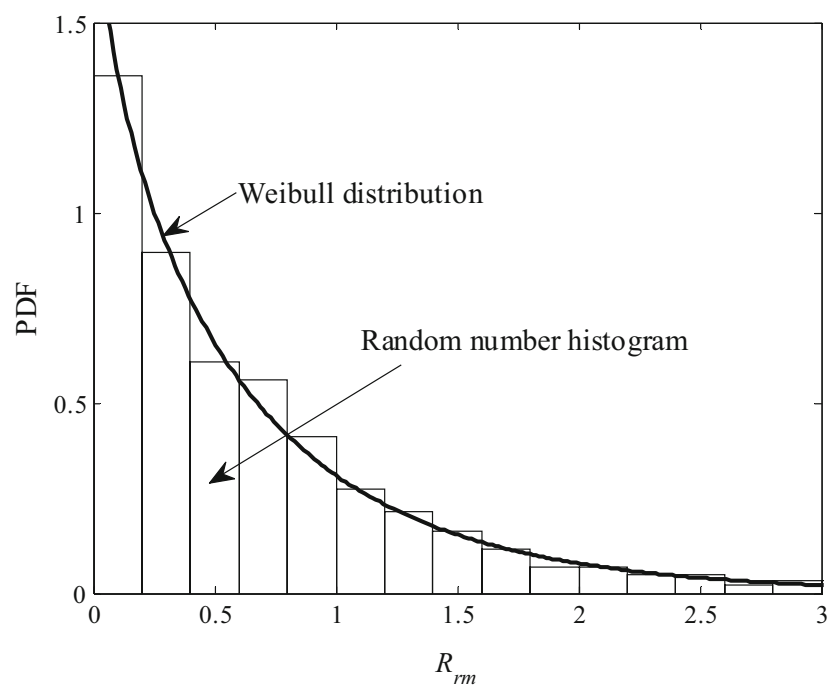

a Probability density distribution of $R_{r m}$

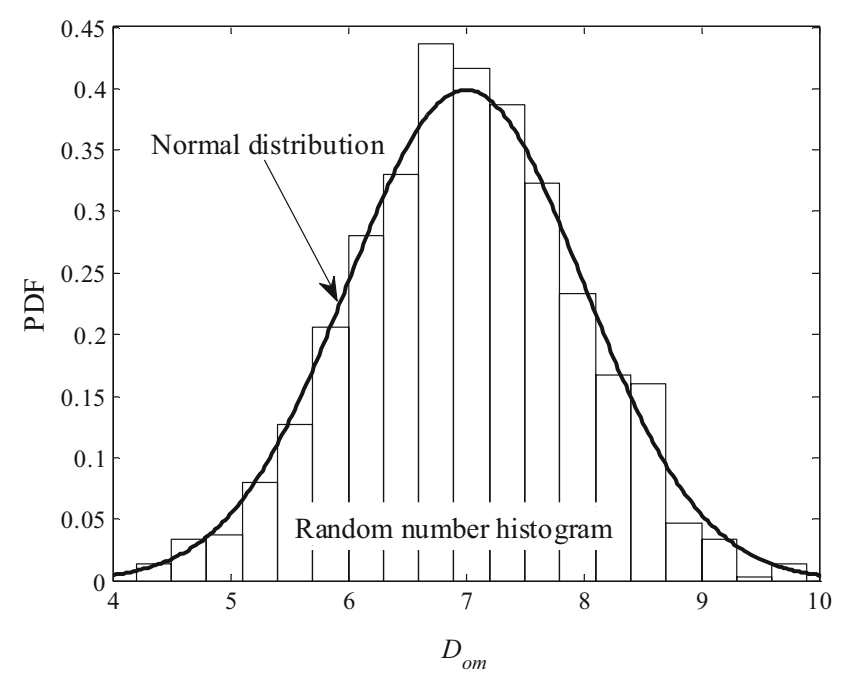

b Probability density distribution of $D_{\text {om }}$ $\left(\times 10^{-6} \mathrm{~mm}^{2} / \mathrm{s}\right)$

Fig. 8 PDF of content and chloride diffusion coefficient of old mortar.

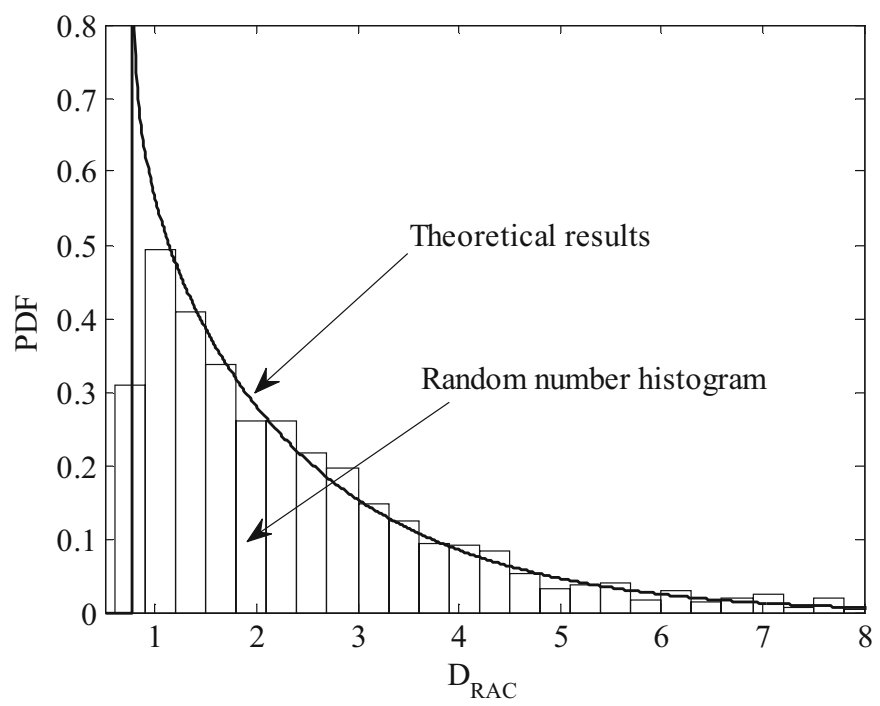

a $D_{\mathrm{RAC}}$ distribution transformed from $R_{r m}\left(\times 10^{-6} \mathrm{~mm}^{2} / \mathrm{s}\right)$

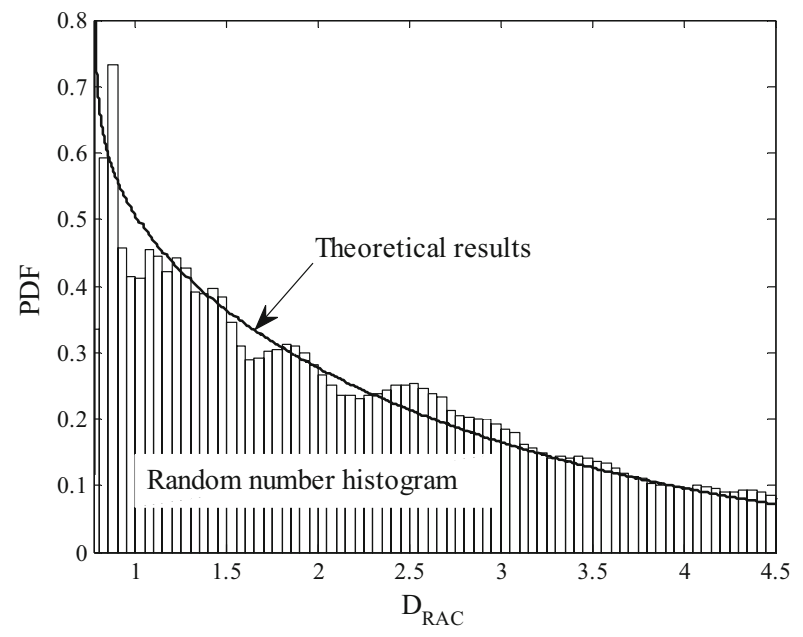

b $D_{\mathrm{RAC}}$ distribution transformed from $R_{r m}$ and $D_{o m}\left(\times 10^{-6} \mathrm{~mm}^{2} / \mathrm{s}\right)$

Fig. $9 D_{\mathrm{RAC}}$ probability density distribution.

of $R_{r m}$ with data A corresponding to Fig. 2a and the PDF of $D_{o m}$ with a Weibull distribution. Other designations are defined similarly. The PDFs of $R_{r m}$ and $D_{o m}$ according to Table 3 are shown in Fig. 10. Let $D_{n m}=2\left(\times 10^{-6} \mathrm{~mm}^{2} / \mathrm{s}\right)$ and $A_{r a}=9 / 64 \pi$. With these inputs, the PDF of $D_{\text {RAC }}$ can be calculated according to Eqs. (31)-(40), as displayed in Fig. 11a.

It can be seen from Fig. 11a that the PDF of $D_{\mathrm{RAC}}$ varies in the range from 0.77 to 3.5 due to the limitations of $R_{r m}$ and $D_{\text {om }}$. The PDF with A-W, C-W and C-N decreases sharply with an increase of $D_{\mathrm{RAC}}$ when $0.77\left(\times 10^{-6} \mathrm{~mm}^{2} /\right.$ $\mathrm{s}) \leq D_{\mathrm{RAC}}<1.2\left(\times 10^{-6} \mathrm{~mm}^{2} / \mathrm{s}\right)$, then it decreases steadily with increasing $D_{\text {RAC }}$ when $D_{\text {RAC }}>1.2\left(\times 10^{-6} \mathrm{~mm}^{2} / \mathrm{s}\right)$. While the PDF with A-N decreases steadily with an increase of $D_{\mathrm{RAC}}$. The reason for this fall may be that both probability distribution of $R_{r m}$ and $D_{o m}$ affect the probability distribution of $D_{\mathrm{RAC}}$, the decrease tendency of $D_{\mathrm{RAC}}$ is corresponding to the old mortar probability distribution in Fig. 10.

The cumulative probability density functions (CDF) of $D_{\text {RAC }}$ can be obtained from Fig. 11a by

$$
C D F\left(D_{\mathrm{RAC}}\right)=\int_{\min \left(\mathrm{D}_{\mathrm{RAC}}\right)}^{D_{\mathrm{RAC}}} f_{D_{\mathrm{RAC}}}\left(D_{\mathrm{RAC}}\right) \mathrm{d} D_{\mathrm{RAC}}
$$

and are presented in Fig. 11b. It can be seen from these figures that the CDF of $D_{\mathrm{RAC}}$ increases with the increase of $D_{\mathrm{RAC}}$. The probability of $D_{\mathrm{RAC}}$ with C-W is larger than the others for a given $D_{\mathrm{RAC}}$ value. Specifically, the probabilities of $D_{\text {RAC }}$ with A-W, C-W, A-N and C-N are $0.86,0.93,0.65$ and 0.85 for a given $D_{\mathrm{RAC}}=2.0\left(\times 10^{-6} \mathrm{~mm}^{2} / \mathrm{s}\right)$, respectively. 
Table 3 Distribution of $R_{r m}$ and $D_{o m}$.

\begin{tabular}{c|c|c}
\hline Series & $\bar{f}_{R_{r m}}\left(R_{r m}\right)$ & $\bar{f}_{D_{o m}}\left(D_{o m}\right)$ \\
\hline \hline A-W & Weibull $\left(R_{r m} \mid 0.6542,0.9189\right)$ & Weibull $\left(D_{o m} \mid 4,2\right)$ \\
\hline A-N & Weibull $\left(R_{r m} \mid 0.6542,0.9189\right)$ & Normal $\left(D_{o m} \mid 7,1\right)$ \\
\hline C-W & Chi squared $\left(R_{r m} \mid 0.5105\right)$ & Noibull $\left(D_{o m} \mid 4,2\right)$ \\
\hline C-N & Chi squared $\left(R_{r m} \mid 0.5105\right)$ & Normal $\left(D_{o m} \mid 7,1\right)$ \\
\hline
\end{tabular}

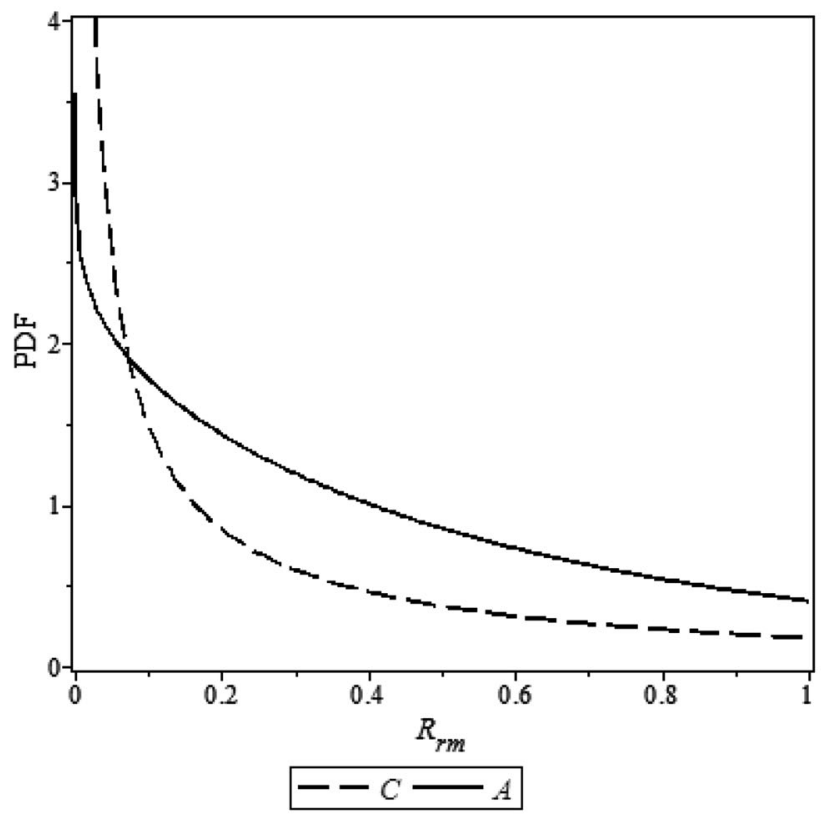

a Probability density distribution of $R_{r m}$

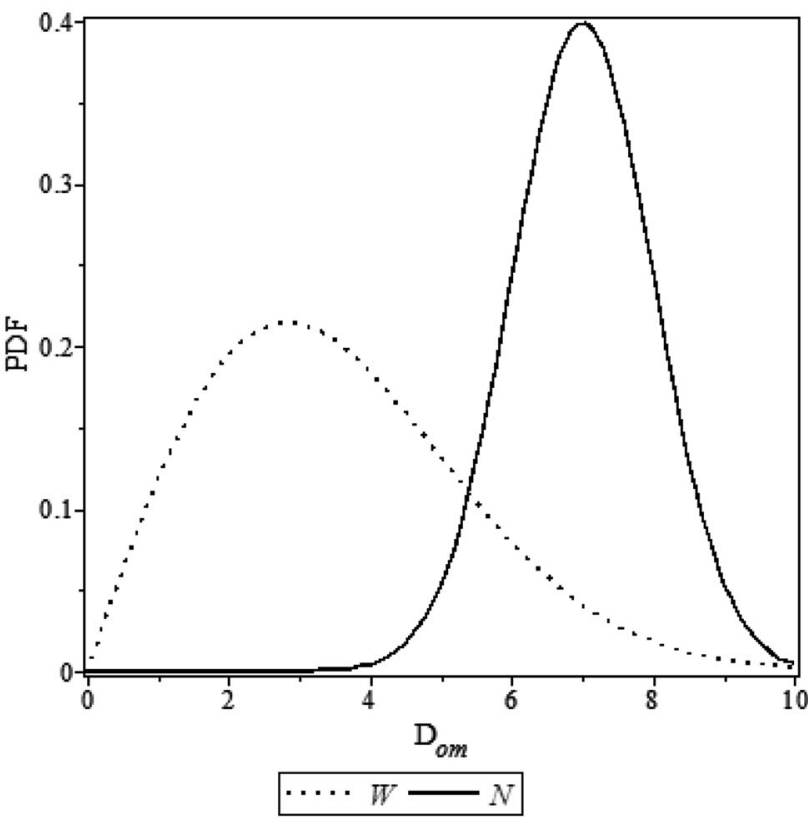

b Probability density distribution of $R_{o m}$

Fig. 10 PDF of $R_{r m}$ and $D_{o m}\left(\times 10^{-6} \mathrm{~mm}^{2} / \mathrm{s}\right)$.

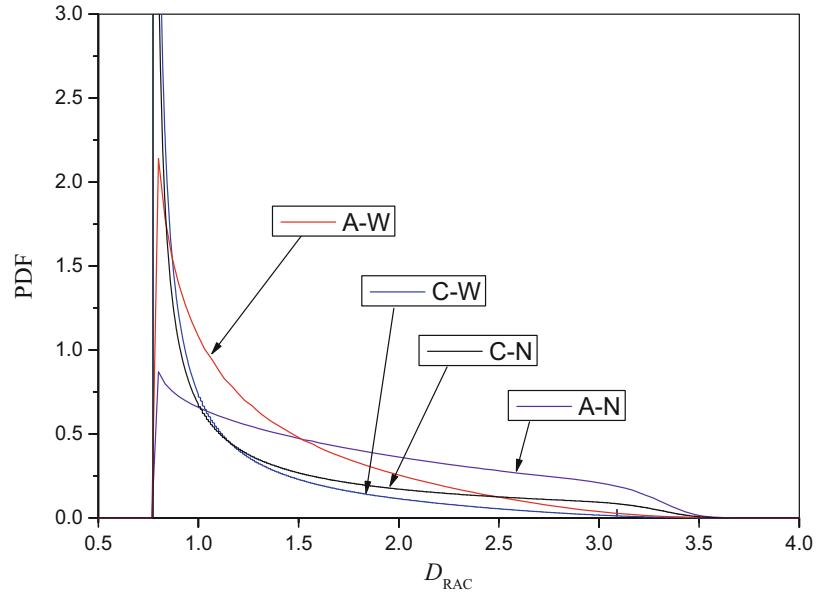

a Probability density distribution of $D_{\mathrm{RAC}}$

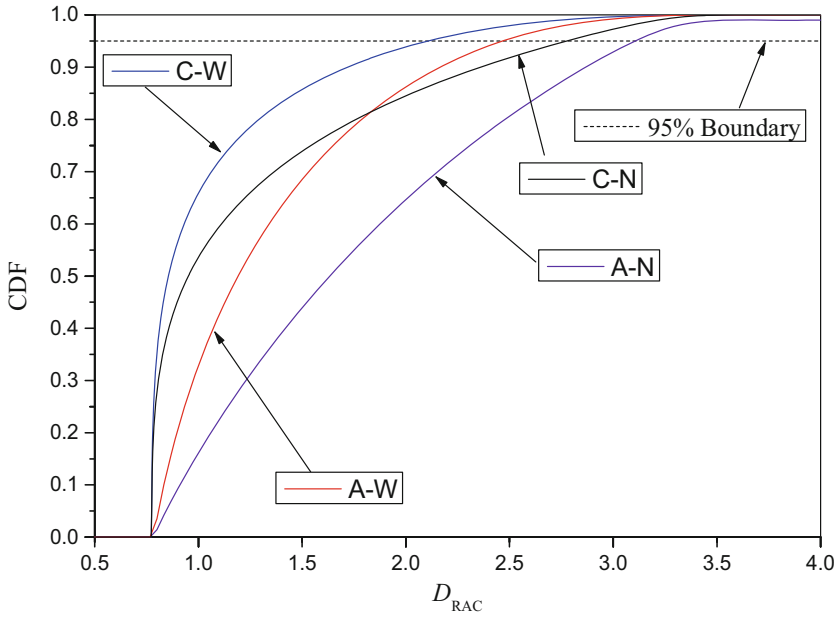

b The cumulative probability density distribution of $D_{\mathrm{RAC}}$

Fig. 11 Probability distribution of $D_{\mathrm{RAC}}\left(\times 10^{-6} \mathrm{~mm}^{2} / \mathrm{s}\right)$.

The accurate evaluation of the chloride diffusion coefficient of concrete is critical for the durability design of concrete, which usually requires a $95 \%$ assurance rate of the $D_{\mathrm{RAC}}$ for reliability. Therefore, the critical value of $D_{R A C}$ can be defined from Fig. 11b. If a $95 \%$ assurance rate is required, the cross points between the line with the $95 \%$ boundary and the lines with A-N, C-N, A-W and C-W can define the critical value of $D_{\mathrm{RAC}}$. Specifically, the $D_{\mathrm{RAC}}$ with a $95 \%$ assurance rate for lines A-W, C-W, A-N, C-N are $2.47,2.11,3.13$ and 2.78 , respectively. Additionally, if 


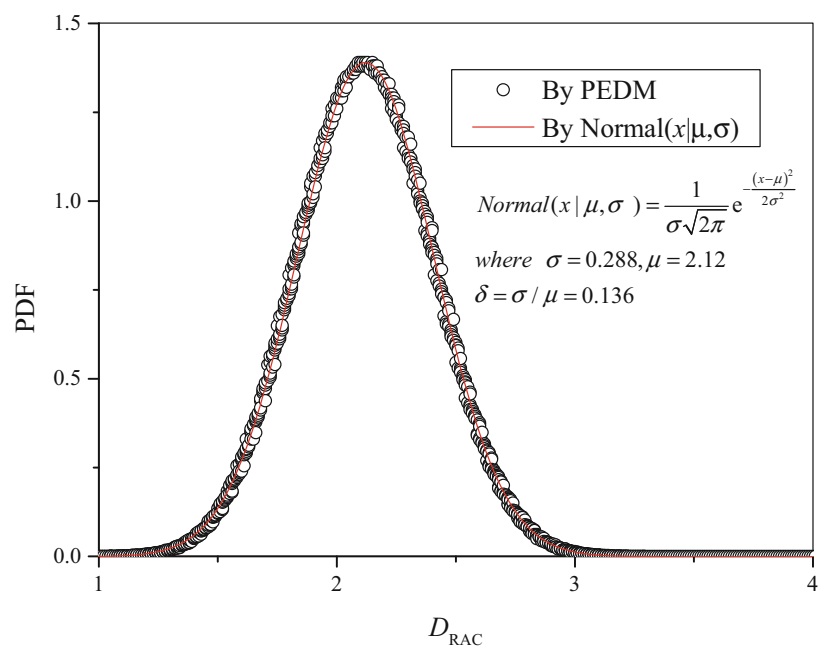

Fig. 12 Probability density distribution of $D_{\mathrm{RAC}}\left(\times 10^{-6}\right.$ $\left.\mathrm{mm}^{2} / \mathrm{s}\right)$.

another assurance rate of $D_{\mathrm{RAC}}$ is needed, this can be performed in a similar way.

\subsubsection{PDEM for Variation of Chloride Diffusion Coefficient}

To investigate the influence of PDEM on the variation of chloride diffusion coefficient of RAC, for simplified analysis, let $R_{r m}$ follow $\operatorname{Normal}\left(R_{r m} \mid 0.5,0.1\right)$ distribution with coefficient of variation 0.2 , and $D_{\text {om }}$ follow $\operatorname{Normal}\left(D_{\text {om }} \mid 7,1\right)$ distribution with coefficient of variation 0.143 , it should be noted that, any kind of probability distribution can be transformed into normal distribution by method of mapping transformation. With these inputs, the PDF of $D_{R A C}$ can be calculated according to Eqs. (22)-(40), and the data calculated by PEDM is fitted by normal distribution, as displayed in Fig. 12.

It can be seen from the figure that, the PDF of $D_{\mathrm{RAC}}$ calculated by PEDM agrees well with Normal distribution, while after probability density evolution, the coefficient of variation of $D_{\mathrm{RAC}}$ with 0.136 is different from that of $R_{r m}$ and $D_{o m}$.

\section{Conclusion}

In this paper, a simplified three-phase composite model has been proposed for predicting the chloride diffusion coefficient of recycled aggregate concrete (RAC). It should be noted that the model will not be appropriate for recycled fine aggregate, whose diameter is less than $5 \mathrm{~mm}$. This investigations revealed that:

- The newly proposed probability density evolution method (PDEM) can be applied to the analysis of the chloride diffusion coefficient for RAC.

- The variation of residual mortar content in RAC is much sensitive to the chloride diffusion coefficient of RAC.

- Weibull function and Chi Square function are suitable for describing the variation of the probability density function (PDF) of chloride diffusion coefficient of RAC.
- The probability distribution of $D_{\mathrm{RAC}}$ can be obtained from the probability distribution of $R_{r m}$ and the probability distribution of $D_{o m}$, and the coefficient of variation of $D_{\mathrm{RAC}}$ is different from that of $R_{r m}$ and $D_{o m}$.

\section{Acknowledgments}

The authors acknowledge the financial support from the National Natural Science Foundation of China (NSFC) (51178340, 51408138), China Postdoctoral Science Foundation, Guangxi Natural Science Foundation (2014GXNSFBA118251). The first author would also like to thank the School of Civil and Environmental Engineering of UNSW.

\section{Open Access}

This article is distributed under the terms of the Creative Commons Attribution 4.0 International License (http://creativecommons.org/licenses/by/4.0/), which permits unrestricted use, distribution, and reproduction in any medium, provided you give appropriate credit to the original author(s) and the source, provide a link to the Creative Commons license, and indicate if changes were made.

\section{References}

Abbas, A., Fathifazl, G., Fournier, B., Isgor, O. B., Zavadil, R., Razaqpur, A. G., \& Foo, S. (2009). Quantification of the residual mortar content in recycled concrete aggregates by image analysis. Materials Characterization, 60(Compendex), 716-728.

Abbas, A., Fathifazl, G., Isgor, O. B., Razaqpur, A. G., Fournier, B., \& Foo, S. (2007). Proposed method for determining the residual mortar content of recycled concrete aggregates. Journal of ASTM International, 5(1), 12.

Breccolotti, M., \& Materazzi, A. L. (2010). Structural reliability of eccentrically-loaded sections in RC columns made of recycled aggregate concrete. Engineering Structures, 32(11), 3704-3712.

Care, S. (2003). Influence of aggregates on chloride diffusivity into mortar. Cement and Concrete Research, 33(7), 1021-1028.

Debieb, F., Courard, L., Kenai, S., \& Degeimbre, R. (2010). Mechanical and durability properties of concrete using contaminated recycled aggregates. Cement and Concrete Composites, 32, 421-426.

Fathifazl, G., Abbas, A., Razaqpur, A. G., Isgor, O. B., Fournier, B., \& Foo, S. (2009). New mixture proportioning method for concrete made with coarse recycled concrete aggregate. Journal of Materials in Civil Engineering, 21, 601-611.

Gokce, A., Nagataki, S., Saeki, B., \& Hisada, M. (2011). Identification of frost-susceptible recycled concrete 
aggregates for durability of concrete. Construction and Building Materials, 25(5), 2426-2431.

Juan, M. S. d., \& Gutierrez, P. A. (2009). Study on the influence of attached mortar content on the properties of recycled concrete aggregate. Construction and Building Materials, 23(2), 872-877.

Kong, J. S., Ababneh, A. N., Frangopol, D. M., \& Xi, Y. P. (2002). Reliability analysis of chloride penetration in saturated concrete. Probabilistic Engineering Mechanics, 17(3), 305-315.

Kong, D. Y., Lei, T., Zheng, J. J., Ma, C. C., \& Jiang, J. (2010). Effect and mechanism of surface-coating pozzalanics materials around aggregate on properties and ITZ microstructure of recycled aggregate concrete. Construction and Building Materials, 24(5), 701-708.

Kou, S. C., \& Poon, C. S. (2006). Compressive strength, pore size distribution and chloride-ion penetration of recycled aggregate concrete incorporating class-F fly ash. $J$ Wuhan Univ Technol, 21(4), 130-136.

Kou, S. C., Poon, C. S., \& Chan. D. (2007). Influence of fly ash as cement replacement on the properties of recycled aggregate concrete. Journal of Materials in Civil Engineering, 19(9), 709-717.

Kou, S. C., Zhan, B. J., \& Poon, C. S. (2014). Use of a CO2 curing step to improve the properties of concrete prepared with recycled aggregates. Cement and Concrete Composites, 45, 22-28.

Li, J. B., Xiao, J. Z., \& Huang, J. (2006). Influence of recycled coarse aggregate replacement percentages on compressive strength of concrete. Journal of Building Materials, 9(3), 297-301 (in Chinese).

Morga, M., \& Marano, G. C. (2015). Chloride Penetration in Circular Concrete Columns. International Journal of Concrete Structures and Materials, 9(2), 173-183.

Muscalu, M., Andrei, R., Lungu, I., Taranu, N., Budescu, M., \& Cazacliu, B. (2013). Technical solutions to improve performance of the recycled cement concrete aggregates for durable road pavements. Environmental Engineering and Management Journal, 12(3), 595-602.

Poon, C. S., Shui, Z. H., \& Lam, L. (2004). Effect of microstructure of ITZ on compressive strength of concrete prepared with recycled aggregates. Construction and Building Materials, 18(6), 461-468.

Seo, T. S., \& Lee, M. S. (2015). Experimental study on tensile creep of coarse recycled aggregate concrete. International Journal of Concrete Structures and Materials, 9(3), 337-343.

Srubar, W. V. (2015). Stochastic service-life modeling of chloride-induced corrosion in recycled-aggregate concrete. Cement Concrete Comp, 55, 103-111.

Tam, V. W. Y., \& Tam, C. M. (2007). A new approach in assessing cement mortar remains on recycled aggregate. Magazine of Concrete Research, 59(6), 413-422.

Tam, V. W. Y., Tam, C. M., \& Le, K. N. (2007). Removal of cement mortar remains from recycled aggregate using presoaking approaches. Resources, Conservation and Recycling, 50(1), 82-101.
Tikalsky, P. J., Pustka, D., \& Marek, P. (2005). Statistical variations in chloride diffusion in concrete bridges. $A C I$ Structural Journal, 102(3), 481-486.

Vancura, M., Khazanovich, L., \& Tompkins, D. (2009). Reappraisal of recycled concrete aggregate as coarse aggregate in concretes for rigid pavements. Journal of the Transportation Research Board, 2113, 49-155.

Walpole, R. E., Myers, R. H., Myers, S. L., \& Ye, K. (2011). Probability \& statistics for engineers \& scientists. Upper Saddle River, NJ: Prentice Hall.

Wardeh, G., Ghorbel, E., \& Gomart, H. (2015). Mix Design and Properties of Recycled Aggregate Concretes: Applicability of Eurocode 2. International Journal of Concrete Structures and Materials, 9(1), 1-20.

Xiao, J. Z., Ying, J. W., \& Shen, L. M. (2012). FEM simulation of chloride diffusion in modeled recycled aggregate concrete. Construction and Building Materials, 29, 12-23.

Xiao, J. Z., Ying, J. W., Tam, V. W. Y., \& Gilbert, I. R. (2014). Test and prediction of chloride diffusion in recycled aggregate concrete. Science China Technological Sciences, 57(12), 2357-2370.

Yehia, S., Helal, K., \& Abusharkh, A. (2015). Strength and durability evaluation of recycled aggregate concrete. International Journal of Concrete Structures and Materials, 9(2), 219-239.

Ying, J., Xiao, J., Shen, L., \& Bradford, M. A. (2013a). Fivephase composite sphere model for chloride diffusivity prediction of recycled aggregate concrete. Magazine of Concrete Research, 65(9), 573-588.

Ying, J., Xiao, J., \& Tam, V. W. Y. (2013b). On the variability of chloride diffusion in modelled recycled aggregate concrete. Construction and Building Materials, 41, 732-741.

Zhang, X. G., Zhao, Y. G., \& Lu, Z. H. (2011). Probabilistic assessment of reinforcing steel depassivation in concrete under aggressive chloride environments based on natural exposure data. Journal of Wuhan University of TechnologyMaterials Science Edition, 26(1), 126-131.

Zheng, J. J. (2000). Mesostructure of concrete: Stereological analysis and some mechanical implications (pp. 1-168). Delft, Netherlands: Delft University.

Zheng, J. J. \& Li, C. Q. (2002). Three-dimensional aggregate density in concrete with wall effect. ACI Materials Journal, 99(6), 568-575.

Zheng, J. J., \& Zhou, X. Z. (2007). Prediction of the chloride diffusivity of concrete. Materials and Structures, 40(7), 693-701.

Zheng, J. J., \& Zhou, X. Z. (2008). Three-phase composite sphere model for the prediction of chloride diffusivity of concrete. Journal of Materials in Civil Engineering, 20(3), 205-211.

Zheng, J. J., Zhou, X. Z., Wu, Y. F., \& Jin, X. Y. (2012). A numerical method for the chloride diffusivity in concrete with aggregate shape effect. Construction and Building Materials, 31, 151-156. 